\title{
NARRATIVA FICCIONAL, EMPATIA E ALTRUíSMO
}

\author{
Fictional narrative, empathy and altruism
}

\author{
Eduardo Vicentini de Medeiros*
}

\begin{abstract}
RESUMO
Parcela significativa da filosofia moral contemporânea e mesmo o senso comum argumentam que a literatura de ficção pode funcionar como instrumento de educação moral. Quando perguntamos sobre a plausibilidade dessa opinião, a explicação invariavelmente passa pelo mecanismo de projeção empática entre o leitor e os personagens da narrativa ficcional. $O$ ato de colocar-se no lugar de um personagem é parte essencial da explicação, sugerindo que a empatia com personagens ficcionais pode produzir empatia com outros seres humanos reais, promovendo, inclusive, motivações altruístas. $\mathrm{O}$ artigo defende uma assimetria radical entre empatia narrativa e empatia inter pares, sugerindo, portanto, que a defesa do papel da literatura de ficção na educação moral seria mais efetiva se não depender de teorias sobre o funcionamento da empatia.
\end{abstract}

Palavras-chave: empatia; moral; ficção.

\begin{abstract}
A significant portion of contemporary moral philosophy and even common sense argue that literary fiction can work as moral education tool. When asked about the plausibility of the opinion, the explanation invariably goes through empathic projection mechanism between the reader and the characters of the fictional narrative. The act of putting ourselves in the shoes of a character is an essential part of the explanation, suggesting that empathy with fictional characters can produce empathy with other real human beings, promoting even altruistic motivations. The article defends a radical asymmetry between narrative empathy and inter pares empathy, sugges-
\end{abstract}

sidade do Vale do Rio dos Sinos.

* Pós-doutorando PNPD Capes. Programa de pós-graduação de Filosofia da Univer- 
ting therefore that the defense of the role of literary fiction in moral education would be more effective if it did not depend on theories about the functioning of empathy.

Keywords: empathy; moral; fiction.

"The weeping of a Russian lady over the fictitious personages in the play, while her coachman is freezing to death on his seat outside, is the sort of thing that everywhere happens on a less glaring scale." (William James, Habit, 1914).

Talvez não seja exagero identificar na filosofia moral contemporânea e, em boa medida, no senso comum das sociedades liberais esclarecidas, uma estratégia similar de aproximação entre narrativa ficcional e educação moral, ou dito de modo mais explícito, a defesa da tese de que o contato continuado com a narrativa ficcional desempenharia função importante na educação moral. Deixando de lado a discussão das formas narrativas do cinema, teatro, pintura e ópera, quero focar em parte dessa estratégia compartilhada que é a criação de uma ponte entre a literatura ficcional e o comportamento moral. Ponte que, caso bem construída, traria os fingidores de todos os matizes de volta à cidadela filosófica, aquietando requentadas desconfianças platônicas.

Na placa comemorativa dessa ponte prodigiosa lemos um elogio da literatura como promotora da educação moral por meio do mecanismo da projeção empática entre um leitor real e personagens ficcionais. O recurso teórico ao mecanismo empático é o que unifica os diferentes filósofos que tenho em mente e seus diversos propósitos. E é sobre o papel que a empatia deveria desempenhar nessa estratégia que trata o presente artigo.

Encontramos a enunciação explícita da estratégia em Moral Imagination -Implications of Cognitive Science for Ethics, de Mark Johnson (1993). Explicando o papel da ficção literária na educação moral, Johnson não apenas utiliza o conceito de imaginação empática para descrever o modo como os leitores "participam da vida" dos personagens, mas dá um passo além defendendo que nossas vidas, quando consideradas temporalmente estendidas, também possuem uma estrutura narrativa. Não apenas as narrativas que lemos, mas também as que vivemos, são o laboratório de aprendizado moral onde percebemos as saliências, os reflexos de nossas diferentes e continuadas decisões e compromissos sobre o bem viver. 
Seguindo por essa via, Johnson recruta dois seminais livros de Martha Nussbaum, The Fragility of Goodness (1986) e Love's Knowledge: Essays on Philosophy and Literature (1990), nos quais parte da estratégia comum é anunciada. Nussbaum explicitamente articula a relação entre narrativa ficcional e aprendizado moral, passando por Ésquilo e Sófocles, Henry James e George Eliot. No entanto, considero-a parcialmente engajada na estratégia comum aqui delineada pelo simples fato de que não encontramos em seus textos a utilização dos conceitos de empatia, simpatia ou simulação imaginativa entre a perspectiva do personagem ficcional e do seu leitor compondo o centro ${ }^{1}$ da explicação do porquê a ficção literária é relevante para a educação moral. E, nesse sentido, a aproximação das posições de Johnson e Nussbaum deve ser feita cum grano salis. Do ponto de vista de Nussbaum, outros são os elementos que entram na explicação: atenção da narrativa ficcional para os detalhes concretos dos cenários deliberativos, o acompanhamento sincrônico do desdobramento de uma situação limite, o enraizamento de uma perspectiva moral em formas de vida que são, simultaneamente, de tessitura complexa e particularizada, a constituição dos dilemas morais as we go along com os personagens. Ao utilizar um vocabulário mais matizado, não utilizando explicitamente o conceito de empatia, Nussbaum adotaria uma posição ligeiramente fora do alvo desse artigo.

Gregory Currie, no influente artigo The Moral Psychology of Fiction (1995), desenvolve uma distinção interessante entre primary e secondary imaginings para defender um ponto próximo ao de Johnson. Imaginações primárias seriam as atividades mentais necessárias para compreensão do que está sendo narrado em uma ficção. Leio o texto e imagino o que está descrito. Um corredor sombrio, por exemplo. Imaginações secundárias são as simulações que o leitor realiza para colocar-se na situação descrita na ficção. Se o leitor estivesse, por exemplo, atravessando um corredor sombrio quais seriam seus pensamentos, sentimentos e atitudes? Feita essa simulação, atribuo esses sentimentos, pensamentos ou atitudes ao personagem que a narrativa descreve atravessando um corredor sombrio. A contribuição da narrativa ficcional para a educação moral reside exatamente no exercício da capacidade de imaginação secundária, essa espécie de empathetic re-enactment (Currie 1995, p. 256) da situação descrita.

Cora Diamond, no artigo Anything but Argument? (1991), utiliza

1 Por vezes Nussbaum utiliza-se do conceito de empatia na margem de uma explicação possível para o papel moral da literatura. Em Cultivating Humanity, lemos: "Hábitos de empatia e conjectura conduzem a um certo tipo de cidadania e a um certo tipo de comunidade: aquela que cultiva um certo tipo de atenção às necessidades dos outros, e compreende o modo como as circunstâncias moldam essas necessidades, enquanto respeitam o isolamento e a privacidade" (Nussbaum, 1997, p.90, minha tradução). Hábitos de empatia que são construídos por meio da imaginação literária. 
conceito similar para explicar o pensamento moral que é próprio de alguns poemas de Wordsworth na coletânea Lyrical Ballads. Uma obra como The old Cumberland Beggar, ao ilustrar o peculiar sentimento de humanidade compartilhada, a compreensão de que todos nós possuímos um coração humano, despertaria no leitor sentimentos similares. Esse contágio sentimental é expressão de um mecanismo empático:

Wordsworth acredita que temos a capacidade de responder com profunda simpatia aos sentimentos de outras pessoas, quando elas são movidas pelas "simples e grandes afecções de nossa natureza", "as paixões essenciais do coração". A representação do poeta de uma pessoa sob influência de tal sentimento pode excitar em nós um sentimento apropriado tanto ao que é descrito quanto à nossa própria natureza, sendo essa propriedade algo que podemos em parte vir a reconhecer por meio do tipo de prazer que o poema nos dá (Diamond, 1991, p. 298).

Não é meu propósito discutir ou fazer exegese dos autores exemplificados. Suas posições são bem mais sofisticadas e nuançadas do que a versão simplificada que passo a discutir, resumindo a estratégia comum em duas teses:

T1: a leitura de narrativa ficcional potencializa a capacidade de projeção empática;

T2: a projeção empática, potencializada pela leitura de narrativa ficcional, motiva ações altruístas.

Meu objetivo é exibir algumas dificuldades para T1 e T2 e, consequentemente, criar obstáculos para a adesão à estratégia comum que as toma por base. O primeiro passo metodológico é reconhecer que são teses empíricas sobre o comportamento daqueles que leem ficção e, portanto, a pergunta crítica que precisamos responder é: quais são as evidências que as diferentes ciências do comportamento oferecem para plausibilidade de T1 e T2?

Antes da resposta, um interlúdio a priori para afastar ambiguidades no uso do conceito de empatia. Para todos os fins, utilizarei o conceito de acordo com um protocolo experimental reconhecidamente aceito, o Índice de Reatividade Interpessoal (The Interpersonal Reactivity Test - IRI) desenvolvido por Mark H. Davis (1980) ${ }^{2}$. O teste é estruturado com sete perguntas de

2 Agradeço a Gabriel Mograbi por sua discussão sobre IRI em Mograbi, 2015. 
autodeclaração para cada uma das quatro subescalas seguintes: (1) Fantasia: mede a tendência para transportar-se imaginativamente para situações ficcionais como livros e filmes; (2) Tomada de Perspectiva: mede habilidade ou propensão para mudar de perspectiva ao lidar com outras pessoas, olhando as situações por mais de um ângulo; (3) Preocupação Empática: mede o grau de compaixão, preocupação e receptividade à situação de terceiros; e (4) Aflição Pessoal: medida das respostas de medo, apreensão e desconforto ao presenciar experiências negativas de terceiros. A resposta a cada uma das vinte e oito perguntas é dada através de uma escala de cinco pontos, variando entre 0 (não me descreve corretamente) e 4 (me descreve corretamente).

Tendo em mente os parâmetros acima, podemos, grosso modo ${ }^{3}$, distinguir dois subtipos de projeção empática:

(a) empatia narrativa: o leitor "sente" o que "sente" um personagem ficcional (parâmetro medido na subescala Fantasia);

(b) empatia inter pares: um agente humano "sente" o que sente outro agente humano ${ }^{4}$ (parâmetro medido, preferencialmente, nas subescalas Preocupação Empática e Aflição pessoal).

Em T1, temos uma ambiguidade sobre qual tipo de empatia é potencializada pela leitura de ficção. Que a leitura potencialize a empatia narrativa parece ser uma precondição da compreensão integral do texto ficcional. Imergir sentimentalmente na leitura, simular a perspectiva dos personagens, ter a emoção que é requisitada por determinadas cenas, são indicativos de um leitor competente. ${ }^{5}$ Por outro lado, se o que T1 afirma é que a leitura potencializa a empatia inter pares, a simulação da perspectiva de outros agentes reais, em situações do dia a dia, a promissória a ser resgatada tem outro preço, bem mais alto. E é nesse sentido que T1 deve ser compreendida. E é nessa direção que objeções são cabíveis. A ambiguidade também contagia T2, e para evitar deformar nosso espantalho, cabe a seguinte reformulação:

3 A distinção não é exaustiva. Forçando alguns limites, podemos pensar em empatia com objetos inanimados, animais de outras espécies, vegetais etc.

4 As aspas cumprem função de marcar uma diferença na fenomenologia desse sentimento. No entanto, não pretendo discutir no que consiste a diferença nem tomar partido entre as teorias concorrentes sobre o caráter bona fide da reação sentimental à ficção ou processos imaginativos em geral.

5 Carroll, 2001, p. 281: "Entender corretamente um texto também envolve mobilizar as emoções que são requisitadas pelo texto. Compreender adequadamente Dr.Wortle's School inclui sentir desconfiança em relação a Robert Lefroy, enquanto que qualquer um que não achar Uriah Heep repugnante em David Copperfield não teria compreendido o ponto de Dickens". 
T1.1: a leitura de narrativa ficcional potencializa a capacidade de projeção empática inter pares;

T1.2 (alternativa): a leitura de narrativa ficcional potencializa a capacidade de projeção empática narrativa;

T2.1: a projeção empática inter pares, potencializada pela leitura de narrativa ficcional, motiva ações altruístas;

T2.2 (subtese): a projeção empática inter pares motiva ações altruístas.

Tal como expressa aqui, considero T2.2 uma reformulação da empathy-altruism hypothesis desenvolvida e defendida por C. Daniel Batson (2011): preocupação empática produz motivação altruísta. A precisão com que Batson define os termos centrais "empatia" e "motivação altruísta" me parece excluir sua aplicação para casos de empatia narrativa. Sendo assim, mesmo que hipótese de Batson seja verdadeira, ela não nos diria nada sobre os efeitos da leitura de ficção, ou seja, não nos diria nada sobre T1.1 ou T2.1.

Com a reformulação proposta para as teses acima, também colocamos um freio em duas inferências intempestivas. A primeira é supor apressadamente ${ }^{6}$ que projeção empática narrativa e empatia inter pares são capacidades correlacionadas, ou seja, que (a) e (b) caem ou permanecem em pé juntas. ${ }^{7}$ Se essa correlação fosse óbvia, poderíamos esperar, igualmente, uma intercorrelação positiva relevante entre a pontuação na subescala Fantasia e a pontuação nas demais subescalas. O que não ocorre. Voltarei a esse ponto com mais vagar ao comentar um interessante artigo de Kohei Nomura e Seiki Akai onde é proposta uma reformulação do teste IRI para empatia narrativa.

A segunda é supor que a empatia inter pares causa x ou y e inferir analogicamente que empatia narrativa causa $\mathrm{x}$ ou $\mathrm{y}$. Pois bem, independentemente de quais eventos ou capacidades sejam x ou y, essa indução é problemática.

É no mínimo razoável pensar em uma assimetria entre (a) e (b).

6 Por "apressadamente", entendo "sem comprovação empírica adequada". (a) exige, no mínimo, compreensão de narrativas orais, quando não alfabetização, enquanto o exercício adequado dessas habilidades não é pré-requisito para (b). Bebês exercitam aspectos afetivos da capacidade empática inter pares - o choro reativo é o caso clássico.

7 Deslize que, a meu ver, é cometido por Kendall Walton: "Algumas obras de arte contêm personagens, seres sencientes ficcionais, e seguidamente respondemos a eles, empatizamos com eles ou os simulamos, praticamente do mesmo modo como fazemos com pessoas reais" (Walton, 2015, p. 142). 
Nossa resposta emocional à literatura (e a projeção empática narrativa é, em parte ${ }^{8}$ uma resposta emocional) é orientada por requisitos formais da narrativa ficcional - algo que não encontramos em nosso contato empático com outros agentes humanos, em eventos reais. ${ }^{9} \mathrm{O}$ ponto de vista do narrador, por exemplo, é um dispositivo formal que condiciona nossa resposta emocional. Pense nas diferenças entre os romances que utilizam o modelo do narrador onisciente e aqueles que apresentam um narrador em primeira pessoa. Pense na possibilidade de comutar a ordem dos eventos narrados, indo e voltando no tempo. Pense na descrição simultânea do fluxo de pensamentos de vários personagens em uma cena. São recursos que, para o bem ou para o mal, não estão disponíveis em nossos contatos do diário.

Se os condicionantes formais da narrativa ficcional não forem suficientes para fixar a assimetria, considere outro argumento, mais pé no chão: a empatia narrativa possui um custo e um risco menor do que a empatia inter pares. Quanto ao custo, na empatia narrativa os principais elementos para identificação e simulação do espectro emocional dos personagens estão dados na própria narrativa; na empatia inter pares, ao contrário, o contato com outros agentes nem sempre possui a dinâmica de um livro aberto. Do lado do risco, um equívoco na empatia narrativa gera a má compreensão de um texto; um equívoco na empatia inter pares pode ocasionar o final de um relacionamento amoroso, uma demissão por justa causa, um arrependimento excruciante.

Deixemos a confortável poltrona apriorista de lado e vejamos o que a pesquisa tem a dizer sobre nossa intuição de assimetria entre (a) e (b).

Mesmo com o esforço elogiável de naturalização dos estudos literários e o interesse crescente da psicologia pela aferição dos efeitos da leitura de ficção, não é tarefa fácil recensear a pergunta específica que me interessa aqui. São poucos os artigos publicados que tocam no tema. Um caso representativo é um artigo publicado em 2012, no qual dois pesquisadores da Universidade de Osaka (Nomura; Akai, 2012) realizaram um experimento que consiste em aplicar o IRI conjuntamente com um teste desenvolvido pelos autores para medir apenas empatia com personagens de ficção (IRI Ficcional) e duas perguntas que medem o apreço por ficção.

Vejamos os propósitos e respectivos resultados do estudo. O primeiro examina a relação entre empatia por pessoas reais e por personagens ficcionais, ou seja, responde nossa questão sobre a relação entre (a) e (b). 0

8 A distinção entre aspectos cognitivos e sentimentais da projeção empática já havia sido delineada por Adam Smith e Herbert Spencer e continua em vigor na pesquisa atual (Davis, 1983, p. 133).

9 Devo esse insight a leitura de Robinson (2005, p. 195-207). 
resultado aponta similaridade de pontuação nas subescalas de Aflição Pessoal, Tomada de Perspectiva e Preocupação Empática, tanto no IRI como no IRI Ficcional, contrário à nossa intuição inicial de que existiria uma assimetria. O segundo propósito examina como a subescala Fantasia no IRI está correlacionada com o apreço por ficção e com empatia por personagens ficcionais. Verificou-se correlação entre apreço por ficção e pontuação em Fantasia, embora não forte o suficiente para tornar provável uma das sub-hipóteses do artigo de que as questões que medem Fantasia no IRI na verdade mediriam apreço por ficção e não uma relação empática com personagens ficcionais. Por sua vez, a relação entre a pontuação em Fantasia e empatia por personagens ficcionais foi estabelecida satisfatoriamente.

O terceiro propósito examina como o apreço por ficção está correlacionado com empatia por pessoas reais e com empatia por personagens ficcionais - perguntas que são versões de T1.1 e T1.2. Por razões similares às nossas, apreço por ficção e empatia por personagens ficcionais andam de mãos dadas no experimento em tela, ou seja, por analogia, T1.2 é bastante plausível. Por outro lado, o estudo mostra correlação estatística relevante entre apreço por ficção e apenas uma das quatro subescalas do IRI. Como esperado, apenas a pontuação em Fantasia acompanha o interesse por narrativas ficcionais daqueles que responderam os questionários, ou seja, ficamos sem um palpite decisivo para aceitar T1.1 com base no estudo em questão.

Do conjunto de resultados, apenas o primeiro me interessa diretamente. Pela razão óbvia que contradiz a motivação básica que me levou a escrever o presente artigo. Afinal de contas, quero permanecer confortavelmente instalado com minha intuição básica da assimetria entre (a) e (b). Para isso, poderia começar pelas objeções de praxe: pouca base estatística (o experimento foi conduzido com apenas 95 participantes), amostragem atípica (todos os participantes eram estudantes da Universidade de Osaka, com idades variando entre 18 e 22 anos), idiossincrasias sociológicas sobre os hábitos de leitura dos japoneses, falta de replicação ou as restrições metodológicas que os próprios autores reconhecem (valores baixos para Alfa de Cronbach, por exemplo). No entanto, o ponto que me chama atenção também é explícito no artigo e me é suficiente: no IRI Ficcional observa-se uma correlação positiva entre Tomada de Perspectiva e Aflição Pessoal, ou seja, na leitura de ficção, quando nos imaginamos no lugar de um personagem em uma situação desagradável, observa-se uma tendência de sentir desconforto ou ansiedade. Na pesquisa que avaliou a métrica do IRI (Davis, 1983), não foi encontrada correlação semelhante. Alta pontuação na Tomada de Perspectiva, quando presenciamos o sofrimento de uma pessoa real, está associada com baixa Aflição Pessoal. Conversamente, valores baixos na Tomada de Perspectiva são acompanhados de escores altos em Aflição Pessoal. Por 
si só, como reconhecem os autores, esse fator indica uma diferença básica entre empatia inter pares e empatia narrativa.

Forçando um pouco meu argumento, mesmo que a pesquisa empírica futura viesse a confirmar que os correlatos neurais de (a) e (b) são idênticos, teríamos como sustentar a assimetria com base em considerações pragmáticas. Caricaturando um pouco: quando jogo xadrez com amigos em um bar ou quando disputo uma partida em um torneio oficial, tenho funcionalmente as mesmas operações em curso, do ponto de vista neuronal. Nem por isso as atividades são similares para todos os propósitos envolvidos.

No entanto, os experimentos de medição e identificação dos correlatos neurais para tarefas de projeção empática, na sua extensa maioria, trabalham com estímulos visuais, narrativas orais e/ou narrativas escritas - ou seja, os estímulos que compõem o cenário daquilo que estou nomeando empatia narrativa. Aliás, de que modo usaríamos ferramentas como fMRI ou fNIRS em protocolos experimentais com situações de empatia inter pares? 0 próprio design dos experimentos em curso parece antes assumir a simetria entre (a) e (b) como uma pressuposição nem sempre discutida. ${ }^{10}$

Quero concluir, novamente instalado no conforto da poltrona apriorista, com a sugestão de que a estratégia aqui discutida, compartilhada pelo senso comum esclarecido e por boa parte da filosofia moral contemporânea, pode constituir ameaça para a desejada autonomia entre valores estéticos e morais. A experiência estética não deveria ser reduzida à capacidade de projeção empática, o que seria uma forma empobrecida de capturar o belo. Justificar a prática da narrativa ficcional exclusivamente por meio de sua pretensa contribuição para edificação moral é uma estratégia equivocada, que minimiza sua função evolutiva para a espécie humana. Por outro lado, é desnecessário assumir uma incomunicabilidade axiológica entre o belo e o bom. É evidente que a criação do belo compartilha valores sociais: a promoção por meio da arte de um sistema particular de crenças religiosas ou políticas constituem os casos mais encontradiços. Mesmo reconhecendo esse truísmo, não estamos obrigados a reduzir a experiência estética, definindo padrões de julgamento do valor da ficção literária com base na sua contribuição para a educação moral. ${ }^{11}$ Podemos estabelecer o vínculo entre ficção e moralidade prescindindo dos mecanismos empáticos tal como sugerido, por exemplo, por Nöel Carroll: nossas crenças e capacidades morais previamente adquiridas preenchem os espaços em branco que toda narrativa deixa por conta do leitor - nesse sentido, a narrativa ficcional participa de

10 Alguns exemplos: Brink et al., 2011; Völlm et al., 2006; e Schnell et al., 2011.

11 Uma discussão dos prós e contras da posição que defende uma autonomia absoluta entre o belo e o bom pode ser encontrada em Carrroll, 2001, p.270-293. 
nossa vida moral não pela aquisição de novas crenças ou sentimento morais particulares, mas pela oportunidade de exercitá-los em cenários hipotéticos, oportunizando aprofundar nossa compreensão dos mesmos, aplicando-os a casos particulares apresentados pela narrativa - o que não deixa de ser uma forma de educação moral - l'éducation sentimentale por excelência. ${ }^{12}$

\section{REFERÊNCIAS}

BATSON, C. D. Altruism in Humans. Oxford: Oxford University Press, 2011.

BRINK, T. T. et al. The Role of Orbitofrontal Cortex in Processing Empathy Stories in 4- to 8-Year-Old Children. Front Psychol, 2:80, 2011.

CARrolL, N. Beyond Aesthetics: Philosophical Essays. Cambridge: Cambridge University Press, 2001.

CURRIE, G. The Moral Psychology of Fiction. Australasian Journal of Philosophy, 73:2, p. 250-259, 1995.

DAVIS, M. H. A Multidimensional Approach to Individual Differences in Empathy.JSAS Catalogue of Selected Documents in Psychology, 10:85, 1980.

Measuring individual differences in empathy: Evidence for a multidimensional approach. Journal of Personality and Social Psychology, 44, p. 113-126, 1983.

DIAMOND, C. The Realistic Spirit. Cambridge: MIT Press, 1991.

JAMES, W. Habit. New York: Henry Holt and Company, 1914.

JOHNSON, M. Moral Imagination - Implications of Cognitive Science for Ethics. Chicago: Chicago University Press, 1993.

MOGRABI, G. J. C. Algumas relações entre Narrativas, Romance e a Psicologia Experimental da Cognição Literária e Habilidades Sociais. Eutomia, 15 (1), p. 123-144, Julho, 2015.

NOMURA, K; AKAI, S. Empathy with Fictional Stories: Reconsiderations of the Fantasy Scale of the Interpersonal Reactivity Index. Psychological Reports, 110:1, p. 304-314, 2012.

NUSSBAUM, M. The Fragility of Goodness. Cambridge: Cambridge University Press, 1986. 1990 .

Love's Knowledge: Essays on Philosophy and Literature. Oxford: Oxford University Press,

. Cultivating Humanity. Cambridge: Harvard University Press, 1997.

ROBINSON, Jenefer. Deeper than Reason - Emotions and Its Role in Literature, Music and Art. New York: Oxford University Press, 2005.

12 Carroll (2001, p. 283) dá o nome de clarificationist view para esse modo de colocar a relação entre narrativa e moralidade. 
SCHNELL, $K$ et al. Functional relations of empathy and mentalizing: an fMRI study on the neural basis of cognitive empathy. Neuroimage, 15:54(2), p. 1743-54, 2011.

VÖLLM, B.A et al. Neuronal correlates of theory of mind and empathy: a functional magnetic resonance imaging study in a nonverbal task. Neuroimage, 1:29, p. 90-8, 2006.

WALTON, Kendall. In Other Shoes - Music, Metaphor, Empathy, Existence. Oxford: Oxford University Press, 2015.

Submetido em: 08/03/2016

Aceito em: 28/04/2016 